\title{
IoT Based Home Security System
}

\author{
Anju P.S ${ }^{1}$, Midhuna Subart ${ }^{2}$, Nasiya Y Salim ${ }^{3}$,Dr. Vince Paul ${ }^{4}$ \\ B. Tech Student, Department of Computer Science, Universal Engineering College, Vallivattom, India ${ }^{1,2,3}$ \\ Professor, Department of Computer Science, Universal Engineering College, Vallivattom, India ${ }^{4}$
}

\begin{abstract}
In today's rapidly moving world where almost everything is driven by technology, it has become the central and essential part of living. Internet of Things (IoT) conceptualizes the idea of remotely connecting and monitoring real world objects (things) through the internet. With increasing rate of crime, protecting our loved ones and our belongings has become important. Such situations can be solved by exploiting the latest functionalities that current technology has to offer i.e. IOT which provides seamless data communication; remote control ability makes it easier to automate the process of security. Automation of security can be achieved by designing an application on Raspberry Pi and ATmega 328 microcontroller through various sensors such as motion sensor -PIR (Passive Infrared) sensors for detection of any intruder in the house, upon detection an alarm is raised and the owner of the house and notification messages are provided. When it comes to our house, this concept can be aptly incorporated to make it smarter, safer and automated. This project presents the overall design of Home Automation System (HAS) with low cost and wireless system. The smart home concept in the system improves the standard living at home. Whenever a person come in front of the house the PIR motion detector sensor detect the person and a message will send to the house owner and he can see the person through the camera in front of the house. The camera is accessed to the web page and also the light, fan, door lock, alarm can be controlled with the web page. The system intended to control electrical appliances and devices in house with relatively low cost design, user-friendly interface and ease of installation. According to the priority of the person the owner can control the electrical appliances. Those who get the authentication can unlock the door by entering password on the keypad and use the home appliances depending on the priority set by the owner.
\end{abstract}

Keywords: Internet of things; Global system for mobile communication; PIR sensor; Raspberry Pi 3 model B, ATmega 328 microcontroller.

\section{INTRODUCTION}

The primary aim is to develop feasible solution to transform a traditional doorbell into an intelligent bell which provides information of the stranger to home owner thereby enabling him to answer the door through smart phone with easy user interface. The design solution in IoT system is multidisciplinary and is scattered through various domain specific challenges. There are many researches that anticipate the failure of wireless network which is growing as the use of technology evolves. The main factors are network topology, failure of network measurement and cost minimization which decides the efficiency of the network and data delivery. The data delivered or exchanged over internet can be audio, video or an image file. Internet of Things (IoT) conceptualizes the idea of remotely connecting and monitoring real world objects (things) through the Internet. When it comes to our house, this concept can be aptly incorporated to make it smarter, safer and automated. Nowadays home and building automation systems are used more and more. That provide increased comfort especially when employed in a private home. An important factor to consider when we talk about home automation is Security. Home security is a very important feature of home automation and maybe the most crucial one. Home security made drastic changes in the past few decades and continue to advance much more in the coming years. Previously home security systems meant having an alarm that would go off when somebody would break in but a smart secure home can do much more than that. Therefore the main objective of our work is to design a system which can alert the owner and others of an intruder break-in by sending a notification to their smart phones. The owner will also have the ability to stop or start the alarm remotely using just his smart phone. This system will help the users to safeguard their homes by placing the system on the doors and monitoring the activity through their smart phones.

\section{LITERATURE SURVEY}

In [1], Raj G Anvekar and Dr. Rajeshwari M Banakar propose an IoT enabled design framework for security sector. The conceptual model developed for the IoT based Home Security System has been built using the fundamentals of IoT Layered Architecture feature. The system requires extremely low maintenance and can be employed in smart homes of tomorrow. One of the prominent application segment of Internet of Things framework is in the Security Sector. It is important to arrive at a unique low cost solution to prevent theft and ensure security to members of the home. The Internet of Things (IoT) Layered Architecture based design approach assists the system designer to conveniently differentiate the system component requirements distinctly at various layers. This paper highlights the model driven development process for Home Security System. It remarks the uses of customers end application such as Telegram to 
securely transmit information through layers of IoT architecture. This paper aims at providing a low-power, cost effective and unobtrusive IoT based home security system which assists in presence detection, identification and authentication of stranger. The proposed solution makes use of USB Webcam as an image capturing unit, Electric Door Strike as an actuator and Telegram which has an amazing feature as Telegram Bot which provide APIs to build solutions which is compatible with Raspberry Pi IoT infrastructure.

In [2], Ahmed ElShafee, Karim Alaa Hamed presents a design and prototype implementation of new home automation system that uses Wi-Fi technology as a network infrastructure connecting its parts. The proposed system consists of two main components; the first part is the server (web server), which presents system core that manages, controls, and monitors users ${ }^{e e}$ home. Users and system administrator can locally (LAN) or remotely (internet) manages and control system code. Second part is hardware interface module, which provides appropriate interface to sensors and actuator of home automation system. Unlike most of available home automation system in the market the proposed system is scalable that one server can manage many hardware interface modules as long as it exists on Wi-Fi network coverage. System supports a wide range of home automation devices like power management components, and security components. The proposed system is better from the scalability and flexibility point of view than the commercially available home automation system.

In [3] , Jayashri and Arvind proposes the use GSM based security system to enhance the security. It illustrates two methods of home security system, first one has a webcam which captures the motion and sends a mail to the owner of house. Second uses GSM-GPS module to send SMS to the owner with the assistance of sensor and micro-controller. They (2013) have implemented a fingerprint based authentication system to unlock a door. This system helps users by only allowing the users whose fingerprint are authorized by the owner of the house. This system can also be used to monitor who all have used the sensor to gained entry into the house. The system is coupled with a few more home protection features such as gas leakage and fire accidents. Although a good system, fingerprint sensors are expensive and complex (as they need increased sensor resolution) to integrate into an IoT setup. Some experts also argue that only relying on a fingerprint sensor is not wise as it is relatively easy to lift someone ${ }^{\text {ee }}$ fingerprints and replicate them, which is why it is always advised to use fingerprint scanners in a two factor authentication systems where an additional layer of security is available in the form of PIN, pass code, voice recognition, etc.

In [4], author proposed the home appliance control system based on GSM network technology is used for transmission purpose of SMS from the sender to the receiver. SMS sending and receiving is used for universal access of appliances which is allowing breach control at home. A processing unit 8051 microcontroller and a communication module that used GSM module. The SMS issued for status reporting in case of power failure. Mobile user will transmits message SMS using GSM technology and it will call GSM Module and it will get activated. The mode of communication is wireless and main mechanism works on the GSM technology. Cell phone has a SIM card and also consist GSM subscription. User transmits the instructions through SMS and then the system takes action against those given instructions. GSM technology has provide the benefit that the system may be accessible in remote areas as well. The programming and also interfacing of microcontroller has been monitored during the implementation.

In [5] , author designed a standalone embedded board with Android ADK (Accessory Development Kit) at home. The appliances of home are connected to the ADK and the communication is established between the Android mobile device and ADK. The appliances of homes are connected to the input/output ports of the board (EMBEDDED SYSTEM) and their status is passed to the ADK. Accessory mode is a feature of Android OS since version 2.3.4 Gingerbread and 3.1 Honeycomb and above. Software design the main screen has contained a list of functions that could be controlled by the user. The microcontroller board (Arduino ADK) based on the ATmega2560. It contains a USB host interface to connect with Android based phones, and that is based on the MAX3421e IC. The Android Open Accessory Protocol 2.0 with two new features: audio output that is from the Android device to the accessory and it also support for the accessory acting as one or more Human Interface Devices (HID) to the Android device. This project is based upon Android and Arduino platform in which both are FOSS (Free Open Source Software). Include motion sensors for Security systems that will detect an unauthorized movement and it will automatically notify the user through cell phone or the security system.

In [6], Home automation is becoming popular due to its numerous benefits. Home automation refers to the control of home appliances and domestic features by local networking or by remote control. Artificial Intelligence provides us the framework to go real-time decision and automation for Internet of Things (IoT). The work deals with discussion about different intelligent home automation systems and technologies from a various features standpoint. The work focuses on concept of home automation where the monitoring and control operations are facilitating through smart devices installed in residential buildings. Heterogeneous home-automation systems and technologies considered in review with central controller based (Arduino or Raspberry pi), web based, email based, Bluetooth-based, mobile-based, SMS based, ZigBee based, Dual Tone Multi Frequency-based, cloud-based and the Internet with performance.

In [7], In recent years, there has been a growing interest among consumers in the smart home concept. Home automation system represents and reports the status of the connected devices in an intuitive, user-friendly interface allowing the user to interact and control various devices with the touch of a few buttons. Some of the major communication technologies used by today's home automation system include Bluetooth, Wi-MAX and Wireless LAN 
(Wi-Fi), ZigBee, and Global System for Mobile Communication (GSM) .Here we are using Wi-Fi module. It offers the user complete access control of the appliances through a remote interface. Automation is the use of control systems and information technology to control equipment, industrial machinery and processes, reducing the need for the human intervention .

In [8], Internet of Things is a concept where each device is assign to an IP address and through that IP address anyone makes that device identifiable on internet. The Internet is an evolving entity. It started as the "Internet of Computers." Research studies have forecast an explosive growth in the number of "things" or devices that will be connected to the Internet. The resulting network is called the "Internet of Things" (IoT). IoT is having the potential to change the lifestyle of peoples. In day today's life, people prefer more of automatic systems rather than any manual systems. The major elements of IoT based home automation system are Raspberry pi and the Relay along with their driving circuitry. Home automation can be defined as a mechanism removing as much human interaction as technically possible and desirable in various domestic processes and replacing them with programmed electronic systems. Ultimately it is a system that aims to heighten quality of life with the automation of household appliances that may be controlled over the Internet or Telephone.

In [9], IoT has received much attention from scientists, industry and government all over the world for its potential in changing modern day living. IoT is envisioned as billions of sensors connected to the internet through wireless and other communication technologies. The sensors would generate large amount of data which needs to be analysed, interpreted and utilized.

In [10], Home Automation System uses the technology of Internet of Things for monitoring and controlling of the electrical and electronic appliances at home from any remote location by simply using a Smartphone. Implementation of a low cost, flexible home automation system is presented. It enhances the use of wireless communication which provides the user with remote control of various electronic and electrical appliances.

In [11], the author has come up with the technology for home automation and security by using a Bluetooth based system. The home appliances that are to be controlled are connected to the input/output ports of the Arduino BT board via relays. Passwords are provided for the purpose of protection so that only the authorized users can access the home appliances. The python script is used for programming purpose as it is portable and can run on any platform. A feedback circuit is used to indicate the status of the home appliances after receiving a command from the phone. The disadvantages includes: Less Range $(<50)$ for controlling Devices, Pairing Process, and Requires Human Involvement for control. No Remote Control or Monitoring.

In [12], the author's implements home automation system using Arduino board that comes along with various sensors such as PIR motion sensor etc. and uses a GSM technology. The status of all the devices connected is sensed by the Arduino board for further processing. This system ensures home automation and security. Arduino board is an advanced version of microcontroller. It has various disadvantages similar to microcontrollers: Less Friendly Environment for development, Less Flexible, Maintenance Overhead.

In [13], the author's has proposed a home automation system using Arduino board based on IOT domain. This particular system uses an internet protocol-based communication. This system makes use of three operating modes: manual mode, automated mode and security mode. The manual mode is based on web supporting device, automated mode is based on sensor reading and security mode is based on safety. The simple execution is provided by Arduino microcontrollers that are used in this project as compared to other controllers. This particular prototype also uses Wi-Fi routers. The shortcomings are: Less Friendly Environment for development, Less Flexible, Maintenance Overhead.

In [14], the author presents the implementation of WiFi based home automation system. WiFi technology is used for connecting various parts of the infrastructure. The proposed system includes a server where the status of each connected device is updated anytime it changes so that the user or system administrator can remotely control as well as monitor the system. It also includes hardware interface modules for connecting various sensors and actuators. This system provides power management and security. The disadvantages are: since WiFi usage involves a range, it is not possible for remote monitoring. It is not much reliable since the WiFi may go down at any point of time.

In [15], the author has designed a PIC microcontroller using ZigBee technology. The home appliances are controlled by using two technologies namely GSM network technology and speech recognition. In case smoke is detected in the house the SMS is sent to the mobile by using a GSM modem which is connected to the PIC controller. The ZigBee and GSM technologies are used for wireless communication among various modules. The microcontroller senses the signals generated at its pins based on the command received by ZigBee modules. This system is useful in case of fire accidents. It has disadvantages such as: use of Microcontroller - Requires Burning of Code for every Changes, Interface Problems, Maintenance overheads, Low processing power, Less Flexible due to complex architecture.

\section{III.SYSTEM OVERVIEW}

Internet of Things (IoT) conceptualizes the idea of remotely connecting and monitoring real world objects (things) through the internet. When it comes to our house, this concept can be aptly incorporated to make it smarter, safer and automated. This project presents the overall design of Home Automation System (HAS) with low cost and wireless system. The smart home concept in the system improves the standard living at home. Whenever a person come in front 
Vol. 8, Issue 4, April 2019

of the house the PIR motion detector sensor detect the person and a message will send to the house owner and he can see the person through the camera in front of the house. The camera is accessed to the webpage and also the light, fan, door lock, alarm can be controlled with the webpage. The system intended to control electrical appliances and devices in house with relatively low cost design, user-friendly interface and ease of installation. According to the priority of the person the owner can control the electrical appliances. Those who get the authorization can unlock the door by entering password on the keypad and use the home appliances depending on the priority set by the owner.

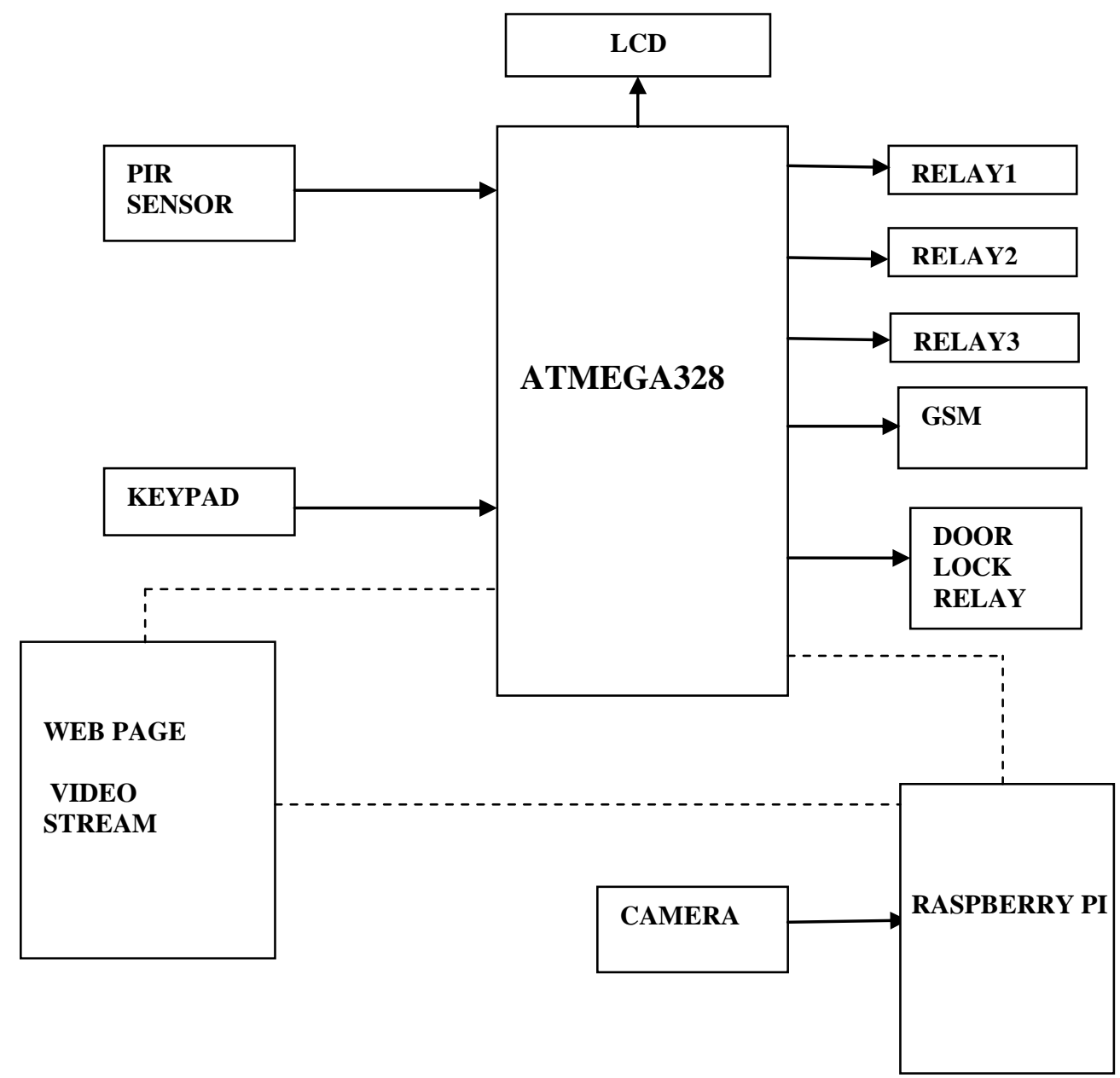

Figure: Block Diagram

\section{IV.METHODOLOGY}

In designing a home security and automation system one or more platforms are used in order to build a reliable and flexible system that can be easily operated and adapted as a security system. Therefore, for the purpose of this project some specific deliberate choices were made on the type of platforms, hardware components and mode of operation of the home security system.

\section{A:PRELIMINARY CONSIDERATIONS}

Before the actual design of the project work, specific deliberate choices in selection of appropriate implementation platforms and hardware components were made. Priority was given to low cost availability, reliability, flexibility and simplicity in all these selections.

\section{B: SYSTEM DESCRIPTION}

The PIR sensor can detect the presence of human being who enter into the house. The Raspberry Pi camera module can capture the images and live streaming videos. The owner can directly login and interact with the webpage and the control unit provided. The images captured and the videos recorded will be directly streamed on user pre-decided 
webpage on smart phone. User can access the video directly using the static IP address or can also stream on local domain with the help of websites.

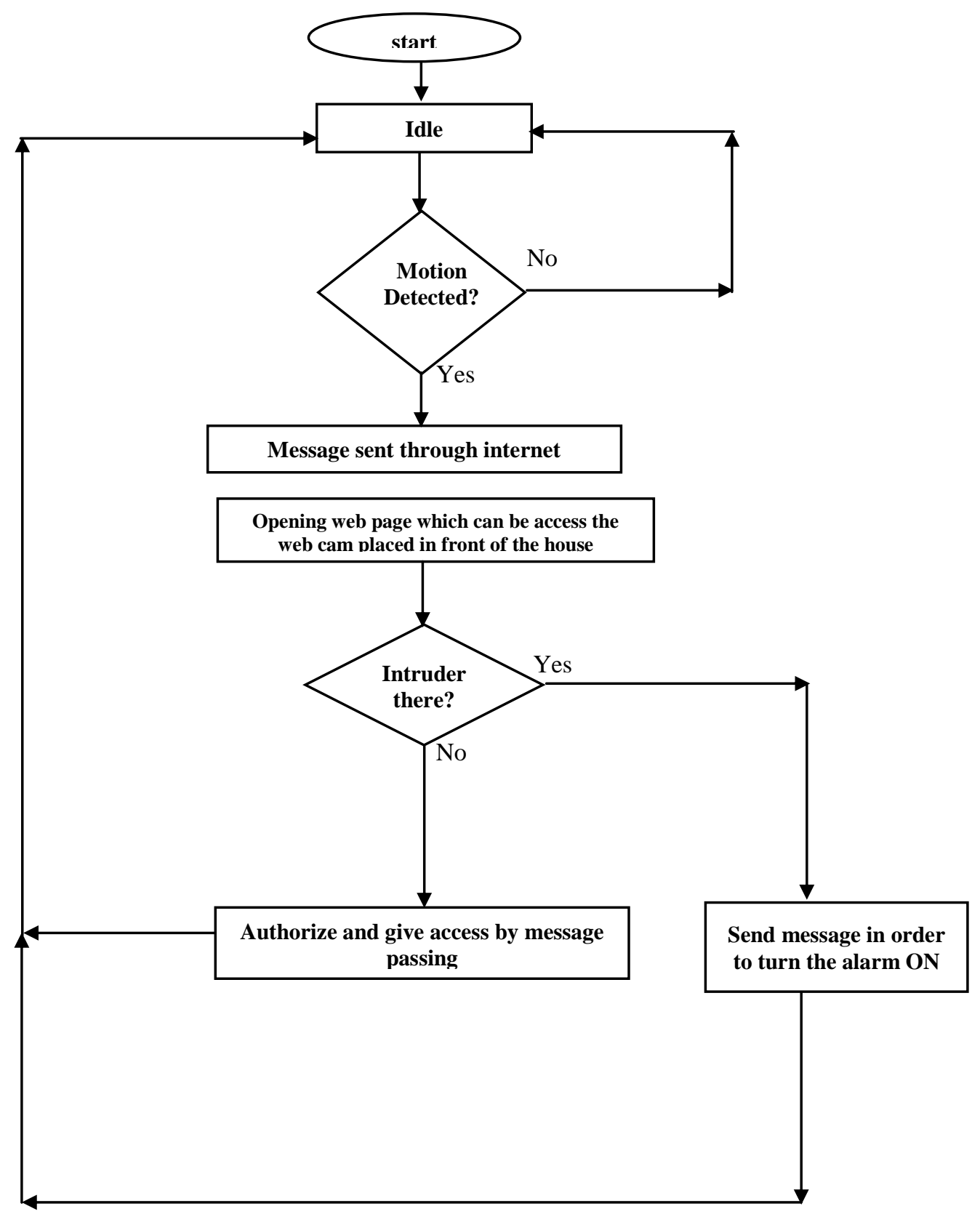

Figure: Flow Chart

\section{Raspberry Pi}

Raspberry Pi board [13] is a miniature marvel, packing considerable computing power into a footprint no larger than a credit card. The processor at the heart of the Raspberry Pi system is a Broadcom BCM2835 system-on-chip (SoC) multimedia processor. This means that the vast majority of the system's components, including its central and graphics processing units along with the audio and communications hardware, are built onto that single component hidden beneath the $512 \mathrm{MB}$ memory chip at the centre of the board. It's not just this SoC design that makes the BCM2835 different to the processor found in your desktop or laptop, however. It also uses a different instruction set architecture (ISA), known as ARM. The Raspberry Pi, by contrast, is designed to run an operating system called GNU/Linux Raspbian. Hereafter referred to simply as Linux. Unlike Windows or OS X, Linux is open source: it's possible to download the source code for the entire operating system and make whatever changes you desire. 
Features of the Raspberry Pi [3] :-

- $\quad \square$ SoC : Broadcom BCM2837

- $\quad$ CPU : 4*ARM cortex-A53,1.2GHz

- $\quad$ CPU: Broadcom Video Core IV.

- $\quad$ RAM :1 GB LPDDR2 (900 MHz)

- $\quad$ Networking : 10/100 Ethernet,2.4 GHz 802.11 n wireless

- Bluetooth: Bluetooth 4.1 classic, Bluetooth low energy.

- $\quad$ Storage: Micro SD.

- $\quad$ GPIO : 40 pin header

- 4 USB ports

- $\quad$ Ethernet port RJ 45

- $\quad$ Full HDMI port

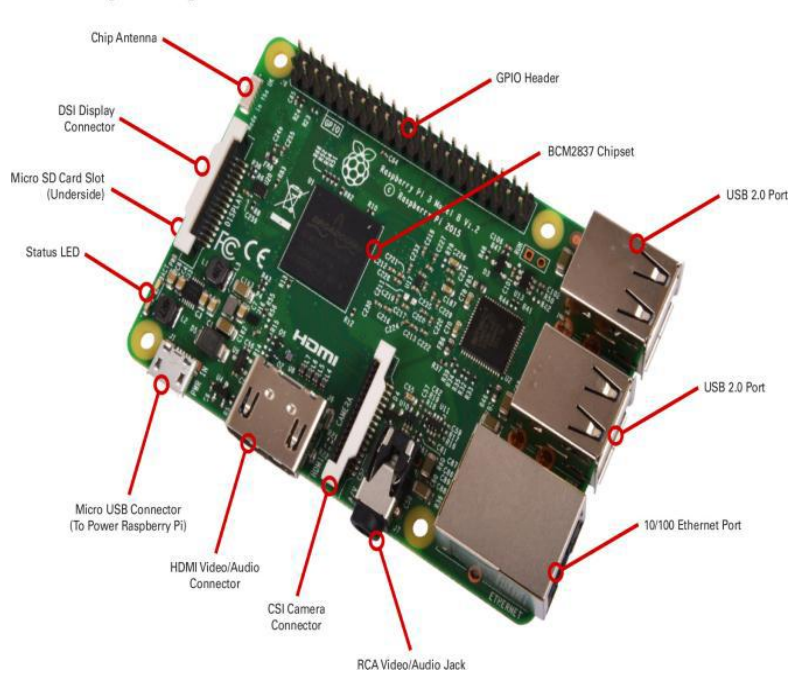

Figure: Raspberry Pi 3 Model B

\section{Raspberry Pi Camera Module}

The Raspberry Pi Camera Module is a custom designed add-on for Raspberry Pi. It attaches to Raspberry Pi by way of one of the two small sockets on the board upper surface. This interface uses the dedicated CSI interface, which was designed especially for interfacing to cameras. The CSI bus is capable of extremely high data rates, and it exclusively carries pixel data.

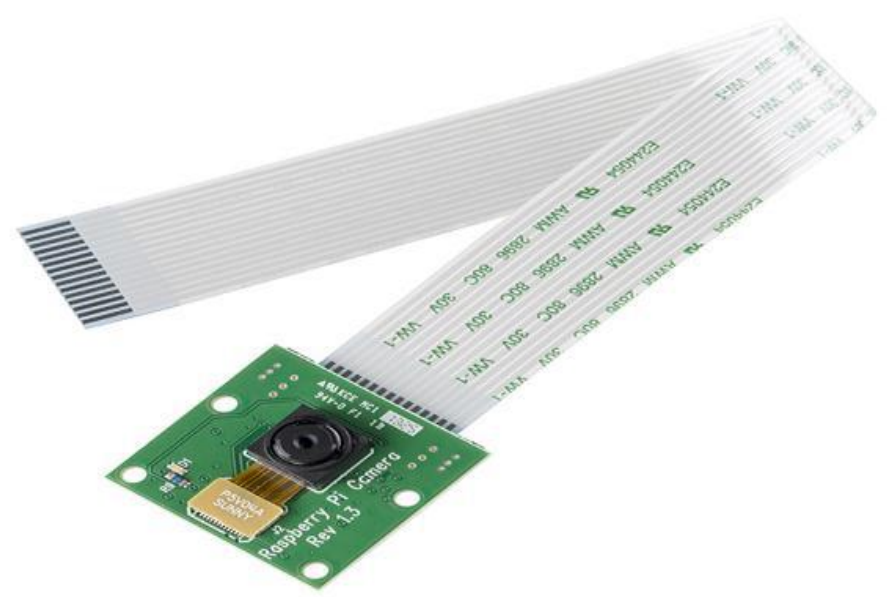

Figure: Raspberry Pi camera module 
Vol. 8, Issue 4, April 2019

\section{ATmega 328 Microcontroller}

ATmega328 is an 8-bit and 28 Pins AVR Microcontroller, manufactured by Microchip, follows RISC Architecture and has a flash type program memory of $32 \mathrm{~KB}$.It has an EEPROM memory of $1 \mathrm{~KB}$ and its SRAM memory is of $2 \mathrm{~KB}$.It has 8 Pin for ADC operations, which all combines to form Port A( PA0 - PA7).It also has 3 built-in Timers, two of them are 8 Bit timers while the third one is 16-Bit Timer. You must have heard of Arduino UNO, UNO is based on atmega328 Microcontroller. It's UNO's heart. It operates ranging from $3.3 \mathrm{~V}$ to $5.5 \mathrm{~V}$ but normally we use $5 \mathrm{~V}$ as a standard. Its excellent features include the cost efficiency, low power dissipation, programming lock for security purposes, real timer counter with separate oscillator. It's normally used in Embedded Systems applications. You should have a look at these Real Life Examples of Embedded Systems, we can design all of them using this Microcontroller. ATmega328 memory: ATmega 328 has three types of memories e.g. EEPROM, SRAM etc.

\section{ATmega328 features :}

- Nonprogrammable data and program memory

- High performance

- Low power conception

- On chip analog comparator

- Advance RISC architecture

- 32KB flash memory

- 2KB SRAM

- Atmega328 has 28 pins in total.

- It has 3 Ports in total which are named as Port B, Port C and Port D.

- Port $\mathrm{C}$ is an analogue Port and it has six pins in total. So, in simple words, ATmega328 has 6 analogue pins.

- Port B and Port D are digital ports and have 7 pins each.

- So, in total ATmega328 has 14 digital pins.

- It also supports Serial Communications, we can perform serial communication via Pin \# 2 (RX) and Pin \# 3 (TX).

- It also supports SPI Protocol.

- It needs a crystal oscillator for generating the frequency. You can use crystal oscillator ranging from $4 \mathrm{MHz}$ to 40 $\mathrm{MHz}$.

- Arduino UNO board uses $16 \mathrm{MHz}$ crystal oscillator.

\section{PIR Motion Sensor}

The PIR (Passive Infra-Red) Sensor is a Pyroelectric device that detects human body motion by measuring changes in the infrared levels emitted by surrounding objects. This motion can be detected by checking for a high signal on a single I/O pin. Incorporating a Fresnel lens and motion detection circuit. High sensitivity and low noise. Output is a standard 5V active low output signal. Module provides an optimized circuit that will detect motion up to 6 meters away Inexpensive and easy to use, The Output can be connected to GPIO pins of Raspberry Pi directly to monitor signal.

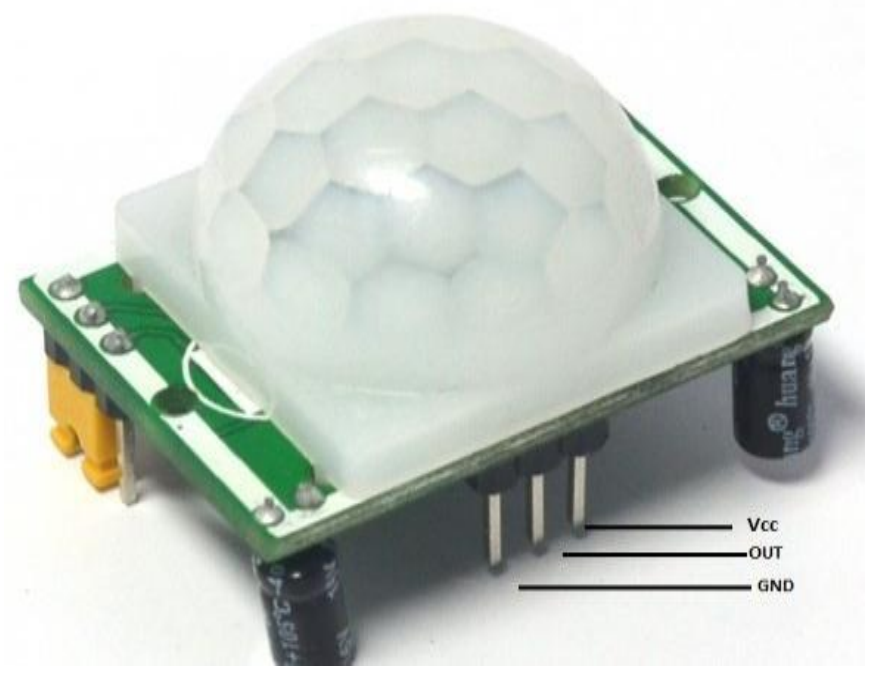

Figure: PIR motion sensor 


\section{IMPLEMENTATION}

The system contains various modules such as PIR sensor, camera module, keypad, webpage, relay, ATmega 328 micro controller, raspberry pi3, GSM module, alarm, notification are discussed in detail below:

$1:$ PIR sensor

PIR motion sensor detects the presence of any human being. Therefore PIR sensor is utilized to detect the presence of intruder in the house.

2: Camera module

The Raspberry Pi camera module can capture the images and live streaming videos. The owner can directly login and interact with the webpage and the control unit provided. The images captured and the videos recorded will be directly streamed on user pre-decided webpage on smart phone.

3: Key pad

The $4 * 3$ keypad provided will allow you to lock and unlock the doors as per the authorization of owner. If authorization got anyone can unlock the door using the appropriate password.

4: Webpage

The camera is accessed to the webpage and also the light, fan, door lock, alarm can be controlled with the webpage. The owner can directly login and interact with the webpage and the control unit provided. The images captured and the videos recorded will be directly streamed on user pre-decided webpage on smart phone.

5: Relay

A relay is an electrically operated switch. When an electric current is passed through the coil it generates a magnetic field that activates the armature and the consequent movement of the movable contact either makes or breaks (depending upon construction) a connection with a fixed contact. If the set of contacts was closed when the relay was de-energized, then the movement opens the contacts and breaks the connection, and vice versa if the contacts were open.

6: ATmega 328 microcontroller

Arduino Uno is a microcontroller board based on the ATmega328P (datasheet). It has 14 digital input/output pins (of which 6 can be used as PWM outputs), 6 analog inputs, a $16 \mathrm{MHz}$ quartz crystal, a USB connection, a power jack, an ICSP header and a reset button.

7: Raspberry Pi 3

The images and videos captured are streamed onto webpage are possible by the usage of Raspberry Pi software. We can setup Raspberry Pi by:

- $\quad$ Insert the microSD card into the card slot on the underside of the Raspberry Pi.

- $\quad$ Plug the USB keyboard into one of the USB ports.

- $\quad$ Plug the USB mouse into one of the USB ports

- $\quad$ Turn on your monitor or TV set and make sure it is set to the proper input (e.g. HDMI 1 or Component

8: GSM module

GSM was designed with a moderate level of service security. The system was designed to authenticate the subscriber using a pre-shared key and challenge-response. Communications between the subscriber and the base station can be encrypted. The development of UMTS introduces an optional Universal Subscriber Identity Module (USIM), that uses a longer authentication key to give greater security, as well as mutually authenticating the network and the user, whereas GSM only authenticates the user to the network (and not vice versa). The security model therefore offers confidentiality and authentication, but limited authorization capabilities, and no non-repudiation.

9: Alarm

The PIR sensor provided will detect the intruder and the owner can see the live streaming video. If the owner found that it is an intruder and he can make alarm by an option in the webpage provided. The owner also can pass the information to police as per need.

10: Notification

If any kind of unusual motion or human detected by the PIR sensor the owner can know it with a notification message. Thus the owner can take correct measures if any problem exists.

\section{VI.RESULT AND DISCUSSION}

The final outcome of this project is a prototype for a simple home security system which can control home appliances with a touch of finger and is equally capable of monitoring with live stream video feed of the webpage. Whenever a person come in front of the house the PIR motion detector sensor detect the person and a message will send to the house owner and he can see the person through the camera in front of the house. The camera is accessed to the webpage and also the light, fan, door lock, alarm can be controlled with the webpage. 
On the front end, there is a microcontroller to control the home appliances and PCB board to which a number of home appliances are connected. Then on the backend, there is a raspberry pi which has been programmed to control the status of GPIO pins and thereby controlling the appliances and also capture video using camera and stream it live to your webpage created. The result of this project have been upto the mark as expected when the project began initially. The user can remotely control the appliances and also watch the stream in the same webpage. Hence the target we set were successfully reached on time effectively.

\section{CONCLUSION AND FUTURE WORK}

Security is of essential importance in today's world, traditional system has attempted to provide the same using technologies such as microcontroller and updated versions of the same. The Proposed System provides Security to the house by detecting the presence of any intruder. If any intruder is detected, an alarm is raised and the owner and law enforcements are notified via message. The proposed work eliminates the overhead associated with traditional system such as high down time during repair and maintenance and any kind of device tampering that an intruder or hacker can do to the system. The proposed work makes use of Raspberry PI as the processor and ATmega 328 microcontroller controller and since it being the latest technology it provides more compatibility with the latest devices and sensor and also provides more room for future enhancement such as exploiting more of Raspberry PI's functionality in areas of efficient consumption of electricity by automating the control of lights for much efficient power management.

Scope of this project can be expanded to many areas by not restricting to only home. The next phase for the Home security and automation market will occur based on a few key improvements in the technology available in automation and security, such as improvement in Wireless Automation solutions as well as lowering of price points as the market begins to accept Home automation and security usage in larger volumes.

\section{ACKNOWLEDGMENT}

This major project would not have been possible without the valuable assistance of many people to whom we are indebted, in particular, our project guide Dr. Vince Paul of Universal Engineering College. We would also like to thank "Department of Computer Science", Universal engineering College for providing maximum support for our project. Our thank also goes to all the teachers of Computer science Department who helped us in many difficult situations regarding the project and provided with the necessary advice.

A special word of thanks is to our class mates and our families for providing us the moral support.

\section{REFERENCES}

[1]. IoT Application Development: Home Security System, Raj G Anvekar School of Electronics and Communication Engineering, KLE Technological University Hubli, India, 2017 IEEE International Conference on Technological Innovations in ICT For Agriculture and Rural Development (TIAR 2017) 978

[2]. Method and Device to Communicate via SMS after a Security Intrusion ,Karri V and Daniel Lim J S 1st International Conf. on Sensing Technology Palmerston North New Zealand2005 21-23

[3]. Design and Implementation of Security for Smart Home based on GSM technology, Jayashri B and Arvind S 2013 International Journal of Smart Home 7 201-08

[4]. Design and Development of Activation and Controlling Of Home Automation System VIA SMS through Microcontroller, Ch.Naga Koti Kumar,www.ijera.com, vol.2, issue2,Marc-apr 2012, pp.1349-1352.

[5]. Home Automation and Security System UsingAndroid ADK, Deepali Javale, Mohd. Mohsin, Shreerang Nandanwar, International Journal of Electronics Communication and Computer Technology (IJECCT) Volume 3 Issue 2 (March 2013).

[6]. Vaishnavi S Gunge and Prathibha S Yalagi, Smart Home Automation, IJCA-0975-8887, National seminar on Recent Trends in Dtamining RTDM 2016.

[7]. Swati Tiwari and Rahul Gedam, Review paper on Home Automation System based on IoT, International Research Journel of Engineering Technology, e-ISSN:2395-0056, p-ISS:2395-0012, volume:03. Issue:05/May 2016.

[8]. Prof. B.P Kulkarni, Aniket V Joshi, Vaibhav V Jadhar and Akshay kumar T Dhamange, IoT Based Home Automation using RPI, International Journal of Innovative Studies in Sciences and Engineering Technology, ISSN:2455-4863, volume:3, Issue:4, April 2017.

[9]. D. Norris, The Internet of Things: Do-It-Yourself at Home Projectsfor Arduino, Raspberry Pi and BeagleBone Black. Tab Electronics, 2015.

[10]. D. Giusto, A. lera, G. Morabito, and L. Atzori, The Internet of Things. New York, NY:Springer New York, 2010.

[11]. A. Z. Alkar and U. Buhur, An Internet based wireless home automation system for multifunctional devices, IEEE Trans. Consum. Electron., vol.51, no.4, pp. 1169-1174, Nov.2005.

[12]. R. Piyare. M. Tazil, Bluetooth Based Home Automation and Security System using Cellphone, 2011 IEEE 15th International Symposium on Consumer Electronics (ISCE), volume.02. Issue:04, August-2011.

[13]. S.Anusha1, M.Madhavi, R.Hemalatha,, „Home Automation Using ATmega328 Microcontroller and Android Application“,International Research Journal of Engineering and Technology (IRJET),Volume: 02,Issue: 06,Sep-2015.

[14]. Harsh Mehta1, Kunal Jhadav, Avinash Mishra,Prof Anushree Deshmukh „IOT Based Home Automation System Using Arduino Board International Research Journal of Engineering and Technology (IRJET), Volume:04, Issue:01, January-2017

[15]. Ahmed ElShafee, Karim Alaa Hamed, „Design and Implementation of a WiFi Based Home Automation System“e, International Journal of Computer and Information Engineering,Volume:06, Issue:08,2012.

[16]. S. Benjamin Arul „Wireless Home Automation System Using ZigBeee, International Journal of Scientific \& Engineering Research, Volume 5,Issue 12,December-2014 